\title{
Evaluation of Community Satisfaction with field-based Primary care Services in a village in North India
}

\author{
Authors \\ Dr Ashish Abraham Thankachan, Dr Isaac Rajesh, Dr Shavinder Singh \\ Corresponding Author \\ Dr Ashish Abraham Thankachan \\ PG Resident, Dept. of Community Medicine, Christian Medical College, Ludhiana \\ Email:docabraham1@gmail.com, Mobile: 963971400
}

\begin{abstract}
Background: Health care systems with a strong foundation of Primary health Care are recognized for improving the overall health of populations. Higher degree of beneficiary satisfaction has always been associated with improved health status and has worked as an important predictor of health outcomes, compliance with treatment and community involvement.

Aims: To assess satisfaction with field-based primary care services currently being implemented in the village of Laltonkalan.

Methodology: This was a cross-sectional study in which interviews were conducted at the community level. For the field survey, a semi-structured questionnaire was used regarding the field services in the village of Laltonkalan using cluster sampling technique. Data was entered in Epi Data and analyzed using SPSS.

Results: Majority of the respondents were female (54.7\%), married (84.7\%) and housewife (43.3\%). More than half of the respondents were between 40-60 years. Majority of the respondents (98.5\%) received Health Education and FP advice and almost $60 \%$ availed Immunization and growth monitoring services. Almost $84 \%$ respondents were very satisfied with the services provided at home. Only $8 \%$ of the respondents did not find the health worker's visit useful for them.

Conclusion: In the study, high level of satisfaction was reported with the services provided in the community however additional services such as house visits by doctor, laboratory investigations and provision of medicines were desired by the participants. The study also revealed that majority of the people did not have any barriers to health but among those who reported having barriers to better health, financial constraints was the most common hindrance.

Keywords: Primary health care, Community, Satisfaction, Health worker, House visits, Field-based.
\end{abstract}

\section{Introduction}

Health care systems with a strong foundation of Primary health Care are recognized for improving the overall health of populations. ${ }^{(1-3)}$ The World Health Organization philosophy of primary health care stresses the importance of involving the community in the development, implementation and evaluation of services. ${ }^{(4)}$ Primary Health Care forms the bedrock of the healthcare services of a country and addresses the majority of a population's health 
needs over time. Primary health care providers should not only ensure that their patients are able to timely access diagnostic, treatment and rehabilitative services but also give high priority to the consumers of community health services and their level of satisfaction with the provided services. ${ }^{(5)}$ Healthcare in India has seen many changes over the years with its objectives evolving according to the requirements of the society and the availability of resources and technology. Consensus is emerging on the need to prioritize primary healthcare as the foundation for health reforms, to focus on prevention and community centered care that will act as a hub for hospital and specialist care. ${ }^{(6)}$ Perception of the beneficiary about quality of care determines whether they seek and continue to use the services. Shortcomings in the delivery of primary healthcare services have often resulted in lesser utilization rates. ${ }^{(7)}$ Several studies have been carried out which have explored the parameters of patient satisfaction in tertiary care centers and large hospitals in India. Little attention has been paid to studies of community satisfaction at the primary care level, especially rural primary care centers linked to hospitals and NGOs which form the bulk of private primary care services. Knowing community expectations would further pave the way for meeting health care demands as well as improving the health status of the population. This study is an attempt to understand community satisfaction in a village in north India.

\section{Aims and Objectives}

The Aim of this study was to assess the community satisfaction with field-based primary care services currently being implemented in the village of Lalton Kalan.

\section{Materials and Methods}

This was a cross-sectional survey. The Community Medicine department in Christian Medical College, Ludhiana provides its field practice area in Lalton Kalan village, with comprehensive primary care and selective secondary care services at the 12-bedded Gurbachan Memorial Hospital (GMH) situated within the village. General out-patient and health services are provided six days a week, through a team of four doctors besides three rotatory medical interns and five staff nurses. Preventive and promotive services are provided at the household level through a team of health workers including an ANM, one LHV and one trained dai.

Community Survey: For the community interviews, geographic mapping of Lalton Kalan village was done and cluster sampling technique was used. Stage 1: Ten out of sixteen clusters were randomly selected from the village each with a sample size of 15 households. Stage 2: The list of households within each selected cluster was obtained from the database maintained by the department and the households were numbered on the list. A random number generator mobile app was used to select a random number from one to the highest numbered household on the list. The household corresponding to the random number selected was then chosen as the first household to visit in the cluster and subsequently consecutive houses were interviewed till the sample size of 15 households was met. Households were considered as a unit of study. The informant was the head of the family or the eldest individual aged 18 years or above who was present at home during the visit. Informed consent was obtained from the participants and interviews were conducted using a structured questionnaire regarding the services received by them. A total of 150 households were interviewed in the community. Data was entered in Epi Data and analyzed using SPSS. Simple percentages were calculated for the responses to the satisfaction questionnaire.

\section{Results}

Majority of the respondents were female $(54.7 \%)$, married $(84.7 \%)$ and housewife $(43.3 \%)$. More than half of the respondents were between 40-60 years and more than one-third had primary education as shown in Table 1. Majority of the respondents (98.5\%) received Health Education and FP advice and almost $60 \%$ availed Immunization and growth monitoring services. Out of the 141 respondents who availed different services there were only 7 
(4.96\%) respondents who utilized ANC and referral services. (Table 2)Almost $84 \%$ respondents were very satisfied with the services provided at home. About $74 \%$ of the respondents desired that the health workers should be accompanied by a doctor, while $70 \%$ of them wanted regular Blood Pressure and Blood Sugar monitoring during their house visits and almost $26 \%$ of them desired to receive medicines at their home from the health-workers. Most of them (86\%) were willing to pay for these additional services while only $14 \%$ refused to bear any cost for the services. About $72 \%$ respondents felt that unclean environment was a major health concern. Majority of the people did not have any barriers to health, among those who reported having barriers to better health, financial constraints (20\%) was the most common hindrance. Only $8 \%$ of the respondents did not find the health worker's visit useful for them.
Table 1. Demographic details of the study respondents in the Community Survey

\begin{tabular}{lc} 
Variables & Community Survey $(n=150)$ \\
\hline Gender & $68(45.3 \%)$ \\
Male & $82(54.7 \%)$ \\
Female & \\
Age Group (years) & $36(24.0 \%)$ \\
$\leq 40$ & $80(53.3 \%)$ \\
$\mathbf{4 1 - 5 9}$ & $34(22.7 \%)$ \\
$\geq \mathbf{6 0}$ & \\
Marital Status & $2(1.3 \%)$ \\
Single & $127(84.7 \%)$ \\
Married & $21(14.0 \%)$ \\
Widow & \\
Education & $49(32.7 \%)$ \\
Illiterate & $55(36.7 \%)$ \\
Primary & $35(23.3 \%)$ \\
Secondary & $9(6.0 \%)$ \\
Senior Secondary & $2(1.3 \%)$ \\
Graduate and above & \\
Occupation & \\
Housewife & $65(43.3 \%)$ \\
Employed & $35(23.3 \%)$ \\
Farmer & $20(13.3 \%)$ \\
Retired & $30(20.0 \%)$ \\
\hline
\end{tabular}

Table 2.Distribution of the services according to the knowledge and availed services by the respondents

\begin{tabular}{|c|c|c|c|c|}
\hline & \multicolumn{4}{|c|}{ Services } \\
\hline & $\begin{array}{l}\text { Anthropometry and Growth } \\
\text { Monitoring }\end{array}$ & Immunization & $\begin{array}{l}\text { ANC and } \\
\text { Referral }\end{array}$ & $\begin{array}{l}\text { Health Education, } \\
\text { Nutrition \& FP advice }\end{array}$ \\
\hline $\begin{array}{l}\text { Knowledge of the } \\
\text { services }(n=150)\end{array}$ & $126(84.00 \%)$ & $128(85.00 \%)$ & $12(8.00 \%)$ & $144(96.00 \%)$ \\
\hline $\begin{array}{l}\text { Availed Services } \\
(n=141)\end{array}$ & $87(61.70 \%)$ & $85(60.28 \%)$ & $7(4.96 \%)$ & $139(98.58 \%)$ \\
\hline
\end{tabular}

*Respondents had multiple responses.

Table 3.Grading of the services received by the respondents $(n=141)$

\begin{tabular}{lc} 
Grading & Frequency \\
\hline Very Unsatisfied & $1(0.70 \%)$ \\
Unsatisfied & $1(0.70 \%)$ \\
Uncertain & $1(0.70 \%)$ \\
Satisfied & $20(14.1 \%)$ \\
Very Satisfied & $118(83.6 \%)$ \\
Total & 141 \\
\hline
\end{tabular}

\section{Discussion}

In the Community interviews, majority of the respondents $(54.7 \%)$ were female showing that women are the most frequently encountered people during the health visits. Most of the respondents belonged to the age group of 41-59 years (53.3\%) and were married $(84.7 \%)$. Educational status of the participants was mainly primary $(36.7 \%)$ and
Table 4. Rating of the Health worker's visit by the respondents $(n=150)$

\begin{tabular}{lc} 
Rating & Frequency \\
\hline Not Useful At All & $7(4.66 \%)$ \\
Not Very Useful & $2(1.33 \%)$ \\
Uncertain & $2(1.33 \%)$ \\
Useful & $18(12.00 \%)$ \\
Very Useful & $121(80.66 \%)$ \\
Total & 150 \\
\hline
\end{tabular}

majority of them were housewives (43.3\%). These findings are consistent with the results of two similar studies done in Delhi and Gujarat which showed that around half of the respondents were female, three-fourths were in the age group of 20-59 years, most with either primary or no education. ${ }^{(6,8)}$ All of the 150 respondents had knowledge about at least one or more health services provided by the 
health workers and about $94 \%$ of them availed these services. The reasons for not utilizing the services included lack of faith in health care, previous unpleasant experience at the centre and absence of any beneficiary of the services in the household. Study done in Delhi in 2006 to assess the awareness of the community about mobile health clinic services found that about $82 \%$ of the respondents were aware about the mobile health clinic but only about $54 \%$ of them had ever utilized the services. ${ }^{(9)}$ In our study the most frequently used health services were Health education, nutrition and family planning advice (98.5\%), anthropometry and growth monitoring $(61.7 \%)$ and immunization services $(60.2 \%)$. Majority of the respondents $(83.6 \%)$ were very satisfied with the services and only $2 \%$ of them were dissatisfied because they did not receive free medicines and concession in treatment. Services Desired -About three-fourth of the respondents wanted doctors to do house visits and monitor BP and blood sugar at home. This was indicative of the community expectations and their health seeking behaviour. Health concerns of the Community and Barriers to Health- There were $72 \%$ of the respondents who felt that unclean environment was the major health concern for the community while about $36 \%$ of them considered contaminated water and adulterated food as the most potential health hazard. The knowledge about the health concerns existed in the community but the initiative to take any measures was lacking. More than three-fourth of the respondents felt that they did not have any barriers to good health while about one-fifth of them reported financial constraints as the biggest barrier to health because of which their quality of life was affected. The visit of the Health workers was found to be useful by almost $90 \%$ of the respondents while only $7 \%$ of them felt that the health workers visit was not useful for them. Health workers serve as an important bridge between the community and the health system and their effectiveness plays an essential role in the delivery of primary health care.

\section{Conclusion}

In the study, high level of satisfaction was reported with the services provided in the community however additional services such as house visits by doctor, laboratory investigations and provision of medicines were desired by the participants. The study also revealed that majority of the people did not have any barriers to health but among those who reported having barriers to better health, financial constraints was the most common hindrance. It is important that in such set-ups all efforts should be undertaken to improve utilization and bring about maximum efficiency of health care delivery.

\section{References}

1. Jaakkimainen RL, Barnsley J, Klein-Geltink J, Kopp A, Glazier RH. Did changing primary care delivery models change performance? A population based study using health administrative data. BMC FamPract. 2011 Jun 3;12(1):1.

2. Starfield B, Shi L, Macinko J. Contribution of primary care to health systems and health. Milbank Q. 2005 Sep 1;83(3):457-502.

3. World Health Organization. The world health report 2008: Primary health care now more than ever. Geneva: World Health Organization; 2008.

4. Poulton BC. Use of the consultation satisfaction questionnaire to examine patients' satisfaction with general practitioners and community nurses: reliability, replicability and discriminant validity. Br J Gen Pract. 1996;46:26-31

5. Bamidele AR, Hoque ME, Van der Heever H. Patient satisfaction with the quality of care in a primary health care setting in Botswana. S AfrFamPract. 2011 Mar 1;53(2):170-5.

6. Rasheed N, Arya S, Acharya A. Client satisfaction and perceptions about quality of health care at a primary health centre of Delhi, India. Indian J Community Health. 2012 Oct 6;24(3):237-42. 
7. Raghunath E, Vijayalakshmi

$\mathrm{S}$, Sathagurunath PA. A study of outpatient satisfaction at primary health centers in Puducherry. Health. 2013 Oct;1(4):118-21.

8. Chandwani $\mathrm{H}$, Jivarajani $\mathrm{P}$, Jivarajani $\mathrm{H}$. Community perception and client satisfaction about the primary health care services in a tribal setting of Gujarat-India. Internet J Health [Internet]. 2009 [cited 2016 Oct 15];9(2):7. Available from: https://print.ispub.com/api/0/ispubarticle/8795

9. Patro BK, Kumar R, Goswami A, Nongkynrih B, Pandav CS, UG Study Group. Community perception and client satisfaction about the primary health care services in an urban resettlement colony of New Delhi. Indian J Community Med. 2008 Oct 1;33(4):250-4. 